Gynec. Invest. 1970;1:183-184

\title{
Announcements
}

\section{September 15-17,1971}

Symposium on Gonadotropic Hormones in Endocrine Disorders of Human Reproduction in Smokovec, High Tatras (Czechoslovakia)

This symposium is organized by the Czechoslovak Society for Endocrinology and the Society of Gynaecologists of the Czechoslovak Medical Society J.E. Purkynë. Papers can be read in English and in German.

Information: T. Klacansky, M.D., Secretary General, First Clinic for Gynaecology and Obstetrics, Zochova 5, Bratislava (Czechoslovakia)

Marius Tausk Award

Submission of manuscripts for the 1972 Marius Tausk Award of DM 15 000.-sponsored by Organon G.m.b.H., München:

Applicants residing in Europe and less than 30 years of age are invited to submit manuscripts of previously unpublished work in the field of clinical and clinical-experimental endocrinology (with the exception of diabetes mellitus) to the President of the German Society of Endocrinology for 1971/72, Prof. Dr. H.L. Krüskemper, 3 Hannover, Podbielskistrasse 380, Abt. für Klinische Endokrinologie, Dept. Innere Medizin der Medizinischen Hochschule. The manuscripts may be in either German or English language and should be submitted in two copies not later than October 15th 1971. After receipt of the manuscript has been acknowledged the author is free to have his work published by any journal. The statutes for the Marius Tausk Career Development may be obtained from the President of the Society. The Award will be presented at the 18th Symposium of the German Society of Endocrinology in Hannover, 1972. Purified HFSH and HLH Available

The National Institute of Arthritis and Metabolic Diseases announces the availability from the National Pituitary Agency (NPA) of purified Human Pituitary Follicle Stimulating Hormone (HFSH) for parenteral administration. Purified FSH is available in vials containing approximately 57 IU (2nd I.R.P. - H.M.G.). LH contamination is approximately 0.27 IU per vial. This material is designated HFSH LER-862-chymotrypsin digested. Reference: L.E. Reichert, jr., J. Clin. Endocr. 27:1065 (1967).

The National Institute of Arthritis and Metabolic Diseases also announces the availability from the National Pituitary Agency (NPA) of purified Human Pituitary Luteinizing Hormone (HLH) for parenteral administration. Purified LH is available in vials containing approximately 2,000 IU per vial (2nd I.R.P. - H.M.G.). FSH contamination is approximately $2.0 \mathrm{IU}$ per vial. This material is designated HLH LER-1417 (Batch Number 2). Reference: L.E. Reichert, jr., and A.F. Parlow, Endocrinology 74: 236 (1964).

These materials are distributed to investigators from the United States only upon submission and approval of protocols detailing proposed research. There is no charge. Application and FDA (No. 1573) forms can be obtained from the National Pituitary Agency (Suite 503-7, 210 West Fayette Street, Baltimore, Maryland 21201). 